\title{
ATIVIDADE ANTIBACTERIANA IN VITRO DO EXTRATO DE Abarema cochliacarpos (GOMES) BARNEBY \& J.W. GRIMES CONTRA BACTÉRIAS ISOLADAS DE FERIDAS CUTÂNEAS DE CÃES
}

\author{
IN VITRO ANTIBACTERIAL ACTIVITY OF THE EXTRACT OF Abarema \\ cochliacarpos (GOMES) BARNEBY \& J.W. GRIMES AGAINST BACTERIA \\ ISOLATED FROM SKIN WOUNDS IN DOGS
}

\author{
Rodrigo Ferreira Lima Tenório ${ }^{1 *}$ \\ Márcia Silva do Nascimento ${ }^{2}$ \\ José Vitor Moreira Lima Filho ${ }^{3}$ \\ Maria Bernadete de Sousa Maia ${ }^{4}$ \\ Maria Cristina de Oliveira Cardoso Coelho ${ }^{5}$ \\ ${ }^{1}$ Programa de Pós-Graduação em Ciência Veterinária, Universidade Federa Rural de Pernambuco, Recife, PE, \\ Brasil. \\ ${ }^{2}$ Departamento de Antibióticos, Universidade Federal de Pernambuco, Recife, PE, Brasil. \\ ${ }^{3}$ Departamento de Biologia, Universidade Federal Rural de Pernambuco, Recife, PE, Brasil. \\ ${ }^{4}$ Departamento de Fisiologia e Farmacologia, Universidade Federal de Pernambuco, Recife, PE, Brasil. \\ ${ }^{5}$ Departamento de Medicina Veterinária, Universidade Federal Rural de Pernambuco, Recife, PE, Brasil. \\ ${ }^{*}$ Autor para correspondência: rodrigofltenorio@yahoo.com.br
}

\section{Resumo}

Abarema cochliacarpos é uma espécie nativa do Brasil, pertence à família Leguminosae - Mimosoidae, muito utilizada na medicina popular. Objetivou-se avaliar a atividade antibacteriana in vitro dos extratos ciclohexânico, acetônico e etanólico da casca de Abarema cochliacarpos (Gomes) Barneby \& J.W. Grimes contra bactérias isoladas de feridas cutâneas de cães. A atividade antibacteriana dos extratos foi determinada pelo método de difusão em meio sólido enquanto que a Concentração Mínima Inibitória foi determinada em microplacas. Alíquotas dos poços sem crescimento bacteriano após $24 \mathrm{~h}$ de incubação a $35-37^{\circ} \mathrm{C}$ foram adicionadas em placas com meio de cultura para determinação da Concentração Mínima Bactericida. A análise fitoquímica da planta revelou resultados positivos para alcalóides, flavonóides, saponinas, taninos (condensáveis), terpenos e esteróides. As bactérias isoladas foram: Staphylococcus intermedius, Bacillus sp., Pasteurella sp. e Escherichia coli. Os ensaios in vitro dos extratos da casca de Abarema cochliacarpos mostraram inibição contra as bactérias Gram-positivas Staphylococcus intermedius e Bacillus sp. nas concentrações testadas (100,50, 25, 12,5 e 6,25 mg/mL), exceto para o extrato em ciclohexano que não demonstrou inibição nas concentrações de 12,5 e $6,25 \mathrm{mg} / \mathrm{mL}$ contra o Staphylococcus intermedius. Não houve halos de inibição frente aos isolados Gram-negativos Pasteurella sp. e Escherichia coli. Concluiu-se que os extratos ciclohexânico, acetônico e etanólico da casca de Abarema cochliacarpos mostraram atividade antibacteriana, para a maioria das concentrações testadas, frente às cepas Gram-positivas Staphylococcus intermedius e Bacillus sp. isoladas de feridas cutâneas de cão.

Palavras-chave: ação antibacteriana; barbatimão; fitoquímica; Mimosoidae; taninos.

\begin{abstract}
Abarema cochliacarpos is a native species of Brazil, it belongs to the family Leguminosae - Mimosoidae, and it has been long used in folk medicine. This study aimed to evaluate the in vitro antibacterial activity of cyclohexane, acetone, and ethanol extracts of the bark of Abarema cochliacarpos (Gomes) Barneby \& JW Grimes against bacteria isolated from skin wounds in dogs. The antibacterial activity of the extracts was determined by the diffusion method on solid medium while the Minimal Inhibitory Concentration was determined in microplates. Aliquots of the wells without bacterial growth after 24 hours of incubation at $35-37{ }^{\circ} \mathrm{C}$ were added to plates with culture medium to determine Minimum Bactericidal Concentration. The phytochemical analysis of the plant showed positive results for
\end{abstract}


alkaloids, flavonoids, saponins, tannins (condensed), terpenes and steroids. The isolated bacteria were: Staphylococcus intermedius, Bacillus sp., Pasteurella sp., and Escherichia coli. In vitro assays of the extracts of the bark of Abarema cochliacarpos showed inhibition against Gram-positive bacteria Staphylococcus intermedius and Bacillus sp. concentrations tested (100, 50, 25, 12.5 and $6.25 \mathrm{mg} /$ $\mathrm{mL}$ ) except for the cyclohexane extract that showed no inhibition at concentrations of 6.25 and 12.5 $\mathrm{mg} / \mathrm{mL}$ against Staphylococcus intermedius. There were no zones of inhibition against the Gramnegative bacteria Pasteurella sp. and Escherichia coli. We concluded that the cyclohexane, acetone, and ethanol extracts of the bark of Abarema cochliacarpos showed antibacterial activity for most tested concentrations against the strains Gram-positive Staphylococcus intermedius and Bacillus sp. isolated from skin wounds in dogs.

Keywords: Abarema cochliacarpos; antibacterial action; Mimosoidae; phytochemical; tannins

Enviado em: 03 maio de 2012

Aceito em: 16 março de 2016

\section{Introdução}

A propriedade antisséptica das plantas medicinais e aromáticas e de seus extratos tem sido observada desde a antiguidade, enquanto as informações sobre as tentativas de se caracterizar suas propriedades em laboratório remontam ao início de $1900^{(1)}$. Com o passar do tempo, o conhecimento sobre as plantas evoluiu como consequência, em grande parte, das modernas tecnologias, ocasionando o isolamento sistemático e a caracterização dos princípios ativos contidos nestas fontes vegetais ${ }^{(2)}$. As plantas têm sido uma fonte valiosa de produtos para manutenção da saúde humana, sendo mais difundidas especialmente nos últimos anos, após numerosos estudos com produtos terapêuticos de plantas medicinais ${ }^{(3)}$.

Abarema cochliacarpos é uma espécie nativa do Brasil, pertence à família Leguminosae - Mimosiodae, que apresenta porte arbóreo, atingindo cerca de $8 \mathrm{~m}$ de altura. Ocorre principalmente no litoral da Mata Atlântica, distribuída pelos Estados da Bahia, Espírito Santo e Paraíba podendo ser encontrada na caatinga, no cerrado em campos rupestres, às vezes atingindo altitudes de até 1.100 metros ${ }^{(4)}$. Tratase de uma árvore frondosa de pequeno a médio porte, possuindo folhas compostas, inflorescência em glomérulos globosos, flores ligeiramente amareladas, frutos do tipo legume contorcido e sementes brancas acinzentadas, amplamente utilizada in natura no Brasil como planta medicinal ${ }^{(3)}$. Segundo a União Internacional de Conservação da Natureza e Recursos Naturais - IUCN, ${ }^{(4)}$ a espécie está classificada como vulnerável à extinção.

A espécie é popularmente conhecida como barbatimão, babatenom, barba-de-timão, entre outras, além de ser utilizada na recuperação de áreas degradadas, apresenta grande valor medicinal ${ }^{(3,5-8)}$. No Brasil, outras espécies de barbatimão são conhecidas pelo mesmo nome popular (Stryphnodendron adstringens, S. ovobatum, S. polyphyllum, S. barbatimam, Dimorphandra mollis) e utilizadas para os mesmos fins terapêuticos ${ }^{(7,9)}$. Na medicina caseira, o decocto das cascas desta planta é amplamente empregado na maioria das regiões do Brasil no tratamento da leucorréia, hemorragias, diarréia, hemorróidas, para limpeza de ferimentos e na forma de gotas contra conjuntivite ${ }^{(3,7,9-11)}$. Segundo Silva et al., ${ }^{(7)}$ as propriedades farmacológicas desta planta ainda não foram extensamente investigadas e poucos estudos têm sido relatados. Neste contexto, objetivou-se avaliar a atividade antibacteriana in vitro dos extratos ciclohexânico (ECH), acetônico (EA) e etanólico (EE) da casca de Abarema cochliacarpos (Gomes) Barneby \& J.W. Grimes contra bactérias isoladas de feridas cutâneas em cães.

\section{Material e Métodos}

A identificação da espécie botânica foi realizada no Instituto Agronômico de Pernambuco - IPA, e a exsicata encontra-se depositada no acervo do Herbário IPA - Dárdano de Andrade Lima, sob o número de registro 87.031.

O material foi coletado na Ilha de Itamaracá - PE, nas proximidades da comunidade do Pilar. As cascas foram coletadas pela manhã, acondicionadas em sacos plásticos sob temperatura ambiente, e levados ao Laboratório de Bioterápicos do Departamento de Medicina Veterinária (DMV) da Universidade Federal Rural de Pernambuco (UFRPE). As cascas foram espalhadas em uma superfície lisa recoberta com papel 
madeira à temperatura ambiente por $24 \mathrm{~h}$, em seguida levada à estufa para a desidratação artificial sob temperatura controlada de $50{ }^{\circ} \mathrm{C} / 48 \mathrm{~h}$. O material foi triturado em liquidificador industrial e armazenado em sacos plásticos e levados para o Laboratório de Química de Produtos Naturais da Universidade Federal de Pernambuco (UFPE) para o preparo dos extratos e análise fitoquímica da planta.

Visando à identificação dos metabólitos secundários presentes na casca da planta em estudo, foram realizados testes fitoquímicos baseados na metodologia descrita por $\operatorname{Costa}^{(12)}$. Os compostos analisados estão descritos no Quadro 1.

Quadro 1: Testes utilizados para a identificação dos metabólitos secundários segundo Costa (12)

\begin{tabular}{|ll|}
\hline Classe de compostos & Teste \\
\hline Alcalóides & Dragendorff; Mayer \\
\hline Flavonóides & Shinoda \\
\hline Saponinas & Espuma \\
\hline Taninos & Cloreto férrico \\
\hline Terpenos e esteróides & Liebermann-Buchard \\
\hline
\end{tabular}

Cerca de $500 \mathrm{~g}$ do pó da casca seca foram submetidos à extração à temperatura ambiente, com $2 \mathrm{~L}$ de ciclohexano por 3 dias com troca de solvente a cada 24 horas; em seguida o mesmo procedimento foi realizado com acetona e finalmente com etanol (Figura 1). Os extratos foram concentrados em rotavapor (modelo BUCHI ROTAVAPOR RII), acoplado a uma bomba a vácuo (modelo TECNAL 0581), secos e armazenados em dessecador, pesados e calculados seus rendimentos.

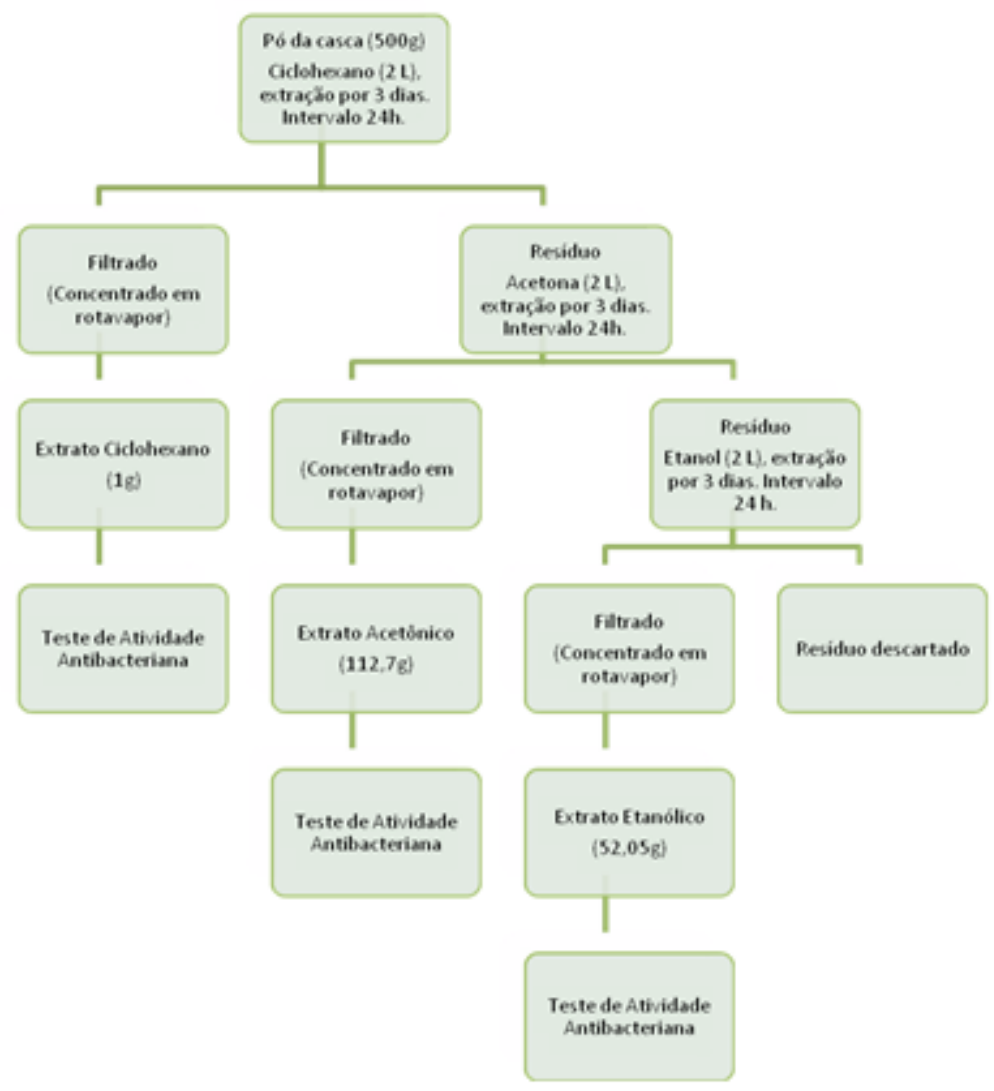

Figura 1: Processo de obtenção dos extratos ciclohexânico, acetônico e etanólico. 
A coleta do material microbiológico foi realizada no Hospital Veterinário do DMV da UFRPE. As amostras foram coletadas de cães que apresentavam traumas com perda cutânea lácero-contusa provocadas por diversas causas. Para a coleta do material bacteriano não houve distinção entre sexo, raça, idade e localização da lesão. Antes de qualquer procedimento, para o tratamento da lesão, foi utilizado suabe estéril na área cruenta percorrendo todo o diâmetro da ferida. Em seguida, o material biológico foi levado ao laboratório de bacteriose do DMV da UFRPE e transferido para placas contendo ágar sangue. As amostras coletadas foram incubadas em estufa a $37^{\circ} \mathrm{C}$ por 24 à $48 \mathrm{~h}$.

A identificação dos isolados foi realizada no Laboratório de Microbiologia e Imunologia - LAMIN da UFRPE, através da análise ao microscópio óptico comum pela técnica de Gram e com auxílio de Kits comerciais (Biomerieux): Kit API 20-E, para a identificação das enterobacteriaceae e outros bacilos, e Kit API Staph, para cocos Gram-positivos. As bactérias identificadas encontram-se no Quadro 2.

Quadro 2: Bactérias isoladas de feridas cutâneas de cães.

\begin{tabular}{|cl|}
\hline Gram-positivos & Gram-negativos \\
\hline Staphylococcus intermedius & Pasteurella sp. \\
\hline Bacillus sp. & Escherichiacoli \\
\hline
\end{tabular}

A atividade antimicrobiana dos extratos foi determinada pelo método de difusão em meio sólido. Colônias isoladas em placas de Petri crescidas por $24 \mathrm{~h} / 37^{\circ} \mathrm{C}$ em meio Ágar Mueller-Hinton foram suspensas em solução tampão PBS e o inóculo padrão foi ajustado na escala 0,5 de McFarland, com aproximadamente $10^{8}$ células $/ \mathrm{mL}$. Em seguida, poços de $5 \mathrm{~mm}$ em diâmetro foram cavados no meio de cultura e, com auxílio de suabe estéril, as culturas foram semeadas na superfície do Agar.

Posteriormente, cada extrato seco foi diluído com Dimetilsulfóxido (DMSO) nas concentrações de $100,50,25,12,5$ e $6,25 \mathrm{mg} / \mathrm{mL}$ e, em seguida, utilizando-se uma pipeta automática, $20 \mu \mathrm{L}$ foram adicionados em cada poço. As placas cultivadas foram deixadas em temperatura ambiente por 20 minutos para facilitar a difusão dos extratos. Após $24 \mathrm{~h}$ de incubação a $37{ }^{\circ} \mathrm{C}$, o diâmetro do halo inibitório ao redor dos discos foi medido com auxílio de uma régua. Os testes foram realizados em duplicata e DMSO foi utilizado como controle negativo.

A Concentração Mínima Inibitória (MIC) foi realizada pelo método de diluição em caldo, utilizandose microplacas de 96 poços contendo Ágar Mueller-Hinton, com concentrações dos extratos ciclohexânico (ECH), acetônico (EA) e etanólico (EE) que variaram de $10-0,0162 \mathrm{mg} / \mathrm{mL}$. O MIC foi a menor concentração do extrato que causou a inibição visível do crescimento; a concentração bactericida mínima (MBC) foi a concentração mais baixa, que resultou em ausência de crescimento após a incubação no período de tempo de $24 \mathrm{~h}$ a $37^{\circ} \mathrm{C}$. Todos os ensaios foram realizados em duplicata.

\section{Resultado e Discussão}

Os extratos apresentaram os seguintes rendimentos: 0,2\% (ECH), 22,54\% (EA) e 10,41\% (EE). A análise fitoquímica da planta revelou resultados positivos para alcalóides, flavonóides, saponinas, taninos (condensáveis), terpenos e esteróides (Quadro 3). Resultados semelhantes foram encontrados por Silva et al.(7), que confirmaram a presença de saponinas, catequinas, taninos, fenóis e antraquinonas, mas constataram ausência de alcalóides e esteróides/triterpenóides. Silva et al. ${ }^{(13)}$, em estudos fitoquímicos por espectrometria de massa e espectroscopia de ressonância magnética nuclear, revelaram que as catequinas são um componente importante na classe dos taninos condensáveis.

Os ensaios da atividade antibacteriana in vitro dos extratos (ECH, EA, EE) da casca de Abarema cochliacarpos mostraram inibição contra a bactéria Gram-positiva Staphylococcus intermedius em todas as concentrações testadas $(100,50,25,12,5$ e $6,25 \mathrm{mg} / \mathrm{mL})$, exceto para o extrato em ciclohexano, que não demonstrou inibição nas concentrações de 12,5 e $6,25 \mathrm{mg} / \mathrm{mL}$. Os extratos apresentaram atividade frente à cepa Gram-positiva Bacillus sp. em todas as concentrações testadas (Tabela 1). 
Quadro 3. Análise fitoquímica de amostras de cascas de Abarema cochliacarpos

\begin{tabular}{|cccl|}
\hline $\begin{array}{c}\text { Classe de Metabólito } \\
\text { Secundário }\end{array}$ & Teste & Resultado & \multicolumn{1}{c|}{ Observação } \\
\hline Alcalóides & Dragendorff & + & $\begin{array}{l}\text { Precipitado laranja } \\
\text { avermelhado. }\end{array}$ \\
\cline { 2 - 4 } & Mayer & + & Precipitado branco. \\
\hline Flavonóides & Shinoda & + & $\begin{array}{l}\text { Leve aparecimento de uma } \\
\text { coloração rósea }\end{array}$ \\
\hline Saponinas & Espuma & + & $\begin{array}{l}\text { Persistência da espuma por } \\
\text { aproximadamente 15 a 20 } \\
\text { minutos. }\end{array}$ \\
\hline Taninos & Cloreto férrico & $\begin{array}{l}\text { Coloraç̃o verde com } \\
\text { precipitado, confirmando a } \\
\text { presençá de taninos } \\
\text { condensáveis. }\end{array}$ \\
\hline Terpenos e Esteróides & Liebermann-Buchard & + & $\begin{array}{l}\text { Leve aparecimento de uma } \\
\text { coloração rósea passando para } \\
\text { overde claro. }\end{array}$ \\
\hline
\end{tabular}

Tabela 1. Halos de inibição (mm) dos extratos ECH, EA, EE da casca de Abarema cochliacarpos pelo método de difusão em meio sólido em diferentes concentrações

\begin{tabular}{|c|c|c|c|c|c|c|c|c|c|c|c|c|c|c|c|c|c|}
\hline & & & & & & iâm & etro & do $\mathrm{Hz}$ & alo de & Inibiç & ição & $(\mathrm{mm})$ & & & & & \\
\hline & & & $\begin{array}{l}\text { Staphy } \\
\text { inter }\end{array}$ & $\begin{array}{l}\text { ylococo } \\
\text { mediu }\end{array}$ & & & Baci & illus s & & Past & steur & rella s1 & & Esch & cheri & ichia c & coli \\
\hline $\begin{array}{r}\text { Concent } \\
\text { ext } \\
(\mathrm{mg}\end{array}$ & $\begin{array}{l}\text { io dos } \\
\text { s }\end{array}$ & Al & A2 & MA & DP & Al & A2 & MA & DP & Al A & A2 & MA I & DP & Al & A2 & MA & DP \\
\hline & 100 & 9 & 11 & 10 & 1,41 & 8 & 8 & 8 & 0,0 & - & - & - & - & - & - & - & - \\
\hline & 50 & 9 & 9 & 9 & 0,0 & 7 & 8 & 7,5 & 0,71 & - & - & - & - & - & - & - & - \\
\hline ECH & 25 & 8 & 9 & 8,5 & 0,71 & 7 & 7 & 7 & 0,0 & - & - & - & - & - & - & - & - \\
\hline & 12,5 & - & - & - & - & 6 & 6 & 6 & 0,0 & - & - & - & - & - & - & - & - \\
\hline & 6,25 & - & - & - & - & 6 & 6 & 6 & 0,0 & - & - & - & - & - & - & - & - \\
\hline & 100 & 17 & 17 & 17 & 0,0 & 17 & 16 & 16,5 & 0,71 & - & - & - & - & - & - & - & - \\
\hline & 50 & 14 & 15 & 14,5 & 0,71 & 15 & 14 & 14,5 & 0,71 & - & - & - & - & - & - & - & - \\
\hline EA & 25 & 12 & 13 & 12,5 & 0,71 & 14 & 13 & 13,5 & 0,71 & - & - & - & - & - & - & - & - \\
\hline & 12,5 & 12 & 11 & 11,5 & 0,71 & 13 & 12 & 12,5 & 0,71 & - & - & - & - & - & - & - & - \\
\hline & 6,25 & 10 & 10 & 10 & 0,0 & 12 & 10 & 11 & 1,41 & - & - & - & - & - & - & - & - \\
\hline & 100 & 16 & 16 & 16 & 0,0 & 16 & 15 & 15,5 & 0,71 & - & - & - & - & - & - & - & - \\
\hline & 50 & 15 & 15 & 15 & 0,0 & 14 & 14 & 14 & 0,0 & - & - & - & - & - & - & - & - \\
\hline EE & 25 & 13 & 13 & 13 & 0,0 & 13 & 13 & 13 & 0,0 & - & - & - & - & - & - & - & - \\
\hline & 12,5 & 12 & 11 & 11,5 & 0,71 & 11 & 11 & 11 & 0,0 & - & - & - & - & - & - & - & - \\
\hline & 6,25 & 8 & 9 & 8,5 & 0,71 & 10 & 10 & 10 & 0,0 & - & - & - & - & - & - & - & - \\
\hline
\end{tabular}

Santos et al. ${ }^{(3)}$ encontraram resultados satisfatórios com o extrato hidroalcoólico da A. cochliacarpos quando aplicados em cepas Gram-positivas (Staphylococcus aureus ATCC6835, Staphylococcus aureus isolados de amostra clínica, Micrococcus luteus). A espécie A. cochliacarpos demonstra eficiência quando testadas contra as cepas Gram-positivas. Santos et al. ${ }^{(14)}$ atribuem a atividade farmacológica aos taninos. A ação de taninos reagindo com a membrana celular de microrganismos e organelas celulares têm sido relatadas por Scalbert ${ }^{(15)}$, que verificaram que a inibição da fosforilação oxidativa por mitocôndrias e a modificação na integridade de membranas na presença de ácido tanínico são os mecanismos responsáveis pelas suas propriedades bactericidas.

Segundo Santos et al. ${ }^{(3)}$, a capacidade de inibição do crescimento bacteriano do extrato da casca de A. cochliocarpos frente às cepas Gram-positivas, provavelmente, pode estar diretamente relacionada com a estrutura da parede celular. Tendo em vista que a principal característica das bactérias Gram- 
negativas é a presença da membrana externa agindo como barreira para certos tipos de antibióticos, enzimas digestivas, detergentes e metais pesados, possivelmente esta membrana protege as bactérias da ação dos extratos de A. cochliocarpos. Silva et al. ${ }^{(16)}$ também confirmam os efeitos inibitórios dos extratos aquoso e metanólico da casca de $A$. cochliocarpos frente às cepas Gram-positivas (Staphylococcus aureus ATCC6835, Staphylococcus aureus de amostras clínicas multirresistentes, Micrococcus luteus) e a Gram-negativa Salmonella choleraesuis.

O teste para a concentração mínima inibitória (MIC) dos extratos ECH, EA, EE foi realizado com as bactérias Staphylococcus intermedius e Bacillus sp., por apresentarem inibição nos testes de sensibilidade. No entanto, o valor do MIC não pode ser determinado, uma vez que os extratos não foram inibitórios em concentrações inferiores a $10 \mathrm{mg} / \mathrm{mL}$ (MIC $>10 \mathrm{mg} / \mathrm{mL}$ ). A Concentração Bactericida Mínima (MBC) foi avaliada com as concentrações de 10,5 e $2,5 \mathrm{mg} / \mathrm{mL}$, havendo crescimento das bactérias em todas as placas incubadas (Figura 3). Resultados diferentes foram encontrados por Santos et al. ${ }^{(3)}$ que apresentaram um MIC de $0,1562 \mathrm{mg} / \mathrm{mL}$ do extrato hidroalcoólico da casca de Abarema cochliacarpos para Micrococcus luteus e de $0,3125 \mathrm{mg} / \mathrm{mL}$ para Staphylococcus aureus ATCC6835. Na Figura 2 observa-se a difusão dos extratos no meio de cultura sem a ocorrência de halo inibitório contra os isolados Gram-negativos Pasteurella sp. e Escherichia coli.

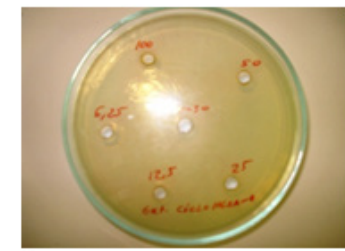

A

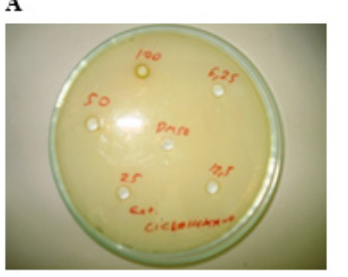

D

Figura 2: Ausência de halo de inibição $(\mathrm{mm})$ frente às bactérias Gram-negativas Pasteurella sp. e Escherichia coli.

A Pasteurella sp. (ECH); B Pasteurella sp. (EA); C Pasteurella sp. (EE); D Escherichia coli (ECH); E Escherichia coli (EA); F Escherichia coli (EE).

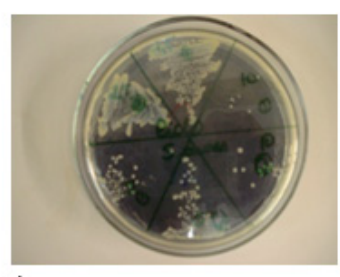

A

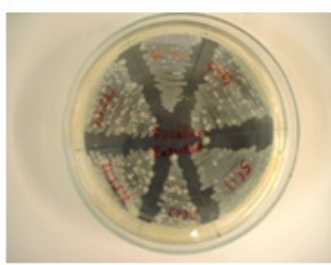

D
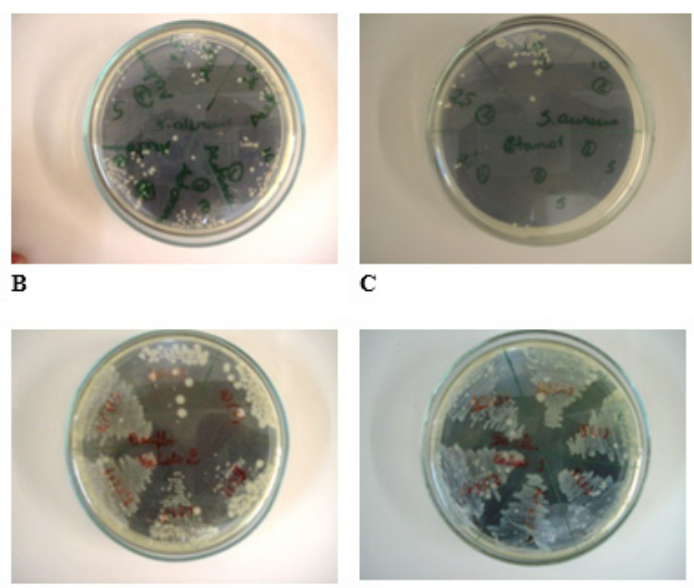

E

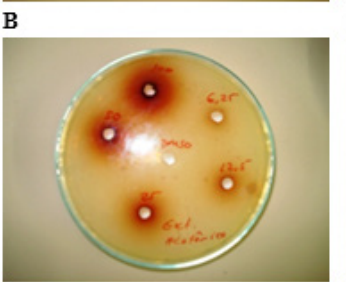

C

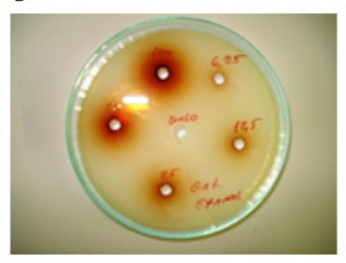
$\mathbf{F}$

Figura 3: Teste de Concentração Bactericida Mínima (MBC) dos extratos $\mathrm{ECH}, \mathrm{EA}$, EE frente às bactérias Staphylococcus intermedius e Bacillus sp. nas concentrações de 10,5 e $2,5 \mathrm{mg} / \mathrm{mL}$ respectivamente.

A Staphylococcus intermedius (ECH); B Staphylococcus intermedius (EA); C Staphylococcus intermedius (EE); D Bacillus sp. (ECH); E Bacillus sp. (EA); F Bacillus sp. (EE). 
Silva et al. ${ }^{(16)}$ relataram um MIC de $5 \mu \mathrm{g} / \mathrm{mL}$ do extrato metanólico para Staphylococcus aureus ATCC6835 e $10 \mu \mathrm{g} / \mathrm{mL}$ para Micrococcus luteus. As diferenças de concentração mínima inibitória podem estar relacionadas ao solvente utilizado para a extração dos metabólitos e também ao tipo de cepa selecionada para os ensaios antibacterianos. No entanto, é necessário purificar, isolar e identificar os componentes bioativos desta planta para novos testes, que atuam na inibição do crescimento de bactérias e na atividade bactericida.

De acordo com os resultados anteriores, a espécie Abarema cochliacarpos, conhecida como barbatimão e utilizada na medicina popular, possui um espectro satisfatório de atividade antibacteriana, principalmente contra cepas Gram-positivas do gênero Staphylococcus.

\section{Conclusão}

Os ensaios desenvolvidos com os extratos ciclohexânico, acetônico e etanólico da casca de Abarema cochliacarpos mostraram atividade antibacteriana, para as concentrações 100, 50, 25, 12,5 e 6,25 mg/ $\mathrm{mL}$ frente às cepas Gram-positivas Staphylococcus intermedius e Bacillus sp. isoladas de feridas de cão.

Abarema cochliacarpos possui potencial farmacológico contra bactérias Gram-positivas, principalmente do gênero Staphylococcus, podendo ser explorada em pesquisas futuras para obtenção de compostos bioativos de ação antibacteriana.

\section{Referências}

1. Dorman HJD, Deans SG. Antimicrobial agents from plants: antibacterial activity of plant colatile oils. Journal os Applied Microbiology. 2000; 88(2): p. 308-316.

2. Costa LB, Tse MLP, Miyada VS. Extratos vegetais como alternativas aos antimicrobianos promotores de crescimento para leitões recém-desmamados. Revista Brasileira de Zootecnia. 2007; 36(3): p. 589-585.

3. Santos SC, Ferreira FS, Rossi-alva JC, Fernandez LG. Atividade antimicrobiana in vitro do extrato de Abarema cochliacarpos (Gomes) Barneby \& Grimes. Revista Brasileira de Farmacognosia. 2007; 17(2): p. 215-219.

4. IUCN. Red List of Threatened Species. [Online].; 2011 [cited 2012 fev 08. Available from: HYPERLINK "www.redlist.org" www.redlist.org .

5. Ardisson L, Godoy JS, Ferreira LAM, Stehmann JR, Brandão MGL. Preparação e caracterização de extratos glicólicos enriquecidos em taninos a partir das cascas de Stryphnodendron adstringens (Mart.) Coville (Barbatimão). Revista Brasileira de Farmacognosia. 2002; 12(1): p. 27-34.

6. Nicioli PM, Nogueira RC, Santana JRF, Silva LC, Silva DPC, PORTO JMP. Ajuste do processo de micropropagação de barbatimão. Ciência Rural. 2008; 38(3): p. 685-689.

7. Silva NCB, Esquibel MA, Alves IM, Velozo ES, Almeida MZ, Santos JES, et al. Antinociceptive effects os Abarema cochliacarpos (Gomes) Barneby \& J. W. Grimes (Mimosaceae). Revista Brasileira de Farmacognosia. 2009; 19(1): p. 46-50.

8. Coelho JM, Antoniolli AB, Silva DN, Carvalho TMMB, Pontes ERJC, Odashiro AN. O efeito da sulfadiazina de prata, extrato de ipê-roxo e extrato de barbatimão na cicatrização de feridas cutâneas em ratos. Revista do Colégio Brasileiro de Cirurgia. 2010; 37(1): p. 045-051.

9. Fonseca P, Librandi APL. Avaliação das características físico-químicas e fitoquímicas de diferentes tinturas de barbatimão (Stryphnodendron barbatiman). Revista Brasileira de Ciências Farmcêuticas. 2008; 44(2): p. 271-277.

10. Souza TM, Moreira RRD, Pietro RCLR, Isaac VLB. Avaliação da atividade anti-séptica de extrato seco 
de Stryphnodendron adstringens (Mart.) Coville e de preparação cosmética contendo este extrato. Revista Brasileira de Farmacognosia. 2007; 17(1): p. 71-75.

11. Lopes GC, Sanches ACC, Toledo CEM, Isler AC, Mello JCP. Determinação quantitativa de taninos em três espécies de Stryphnodendron por cromatografia líquida de alta eficiência. Brazilian Journal os Pharmaceutical Sciences. 2009; 45(1): p. 135-143.

12. Costa AF. Farmacognosia. 2nd ed. Lisboa: Fundação Calouste Gulbenkian; 1982.

13. Santos SC, Costa WF, Batista F, Santos LR, Ferri PH, Ferreira HD, et al. Seasonal variation in the contento os tannins in barks os barbatimão species. Revista Brasileira de Farmacognosia. 2006; 16(4): p. 552-556.

14. Scalbert A. Antimicrobial properties of tannins. Phytochemistry. 1991; 30(12): p. 3875-3883.

15. Silva MS, Sánchez-fidalgo S, Talero E, Cárdeno A, Silva MA, Villegas W, et al. Anti-inflammatory intestinal activity of Abarema cochliacarpos (Gomes) Barneby \& Grimes in TNBS colitis model. Journal of Ethnopharmacology. 2010; 128(2): p. 467-475.

16. Silva NCB, Esquibel MA, Santos JES, Almeida MZ, Sampaio CS, Barros TF. In vitro antimicrobial activity os extracts from Abarema cochliacarpos (Gomes) Barneby and J. W. Grimes. African Journal of Microbiology Research. 2010; 4(15): p. 1654-1658. 